Association for Information Systems

AIS Electronic Library (AISeL)

\title{
Individual Digital Study Assistant for Higher Education Institutions: Status Quo Analysis and Further Research Agenda
}

Christin Karrenbauer

Leibniz Universität Hannover, Information Systems Institute, Hannover, Germany

Claudia M. König

Leibniz Universität Hannover, Information Systems Institute, Hannover, Germany

Michael H. Breitner

Leibniz Universität Hannover, Information Systems Institute, Hannover, Germany

Follow this and additional works at: https://aisel.aisnet.org/wi2021

Karrenbauer, Christin; M. König, Claudia; and H. Breitner, Michael, "Individual Digital Study Assistant for Higher Education Institutions: Status Quo Analysis and Further Research Agenda" (2021).

Wirtschaftsinformatik 2021 Proceedings. 11.

https://aisel.aisnet.org/wi2021/KDigitalEducation15/Track15/11

This material is brought to you by the Wirtschaftsinformatik at AIS Electronic Library (AISeL). It has been accepted for inclusion in Wirtschaftsinformatik 2021 Proceedings by an authorized administrator of AIS Electronic Library (AISeL). For more information, please contact elibrary@aisnet.org. 


\title{
Individual Digital Study Assistant for Higher Education Institutions: Status Quo Analysis and Further Research Agenda
}

\author{
Christin Karrenbauer, Claudia M. König, and Michael H. Breitner \\ Leibniz Universität Hannover, Information Systems Institute, Hannover, Germany \\ \{karrenbauer, koenig, breitner\}@iwi.uni-hannover.de
}

\begin{abstract}
Today, digital assistants can support students during their studies. A quick and easily useable and accessible information transfer, individually tailored to the students' needs is required. Individual educational biographies and an increasing number of students require individual information provision and advice. Research on digital assistance systems has increased dramatically over the past decade. We focus on the individual digital study assistant (IDSA) field with its functionalities embedded in a typical student life cycle (SLC). In order to determine the status quo of DSA, we conduct a literature review with a focus on their functionalities. One research finding indicates that the DSA field generates a wide range of DSA functionalities. We structured them developing a morphological box. Finally, we discuss a further research agenda for the development, adaption, introduction, and success of IDSA.
\end{abstract}

Keywords: Literature Review, Student Life Cycle, Individual Digital Study Assistant, Morphological Analysis, Further Research Agenda

\section{Introduction}

Students today have a wide variety of study courses and courses to choose from, partly due to the Bologna Process and the reforms that have taken place in higher education institutions (HEI). The Bradley Report in Australia initiated similar reorganizations that led to comparable effects. After the mentioned reforms, more students are able to begin their studies regardless of their social and educational background [1-3]. Thus, students' heterogeneity increased and corresponding individualized study needs, goals, and the need for individual support and counseling [4]. However, due to the increasing number of students [2] with a relatively constant number of lecturers [5], [6], personal advice alone is less feasible [7].

In addition, students prefer a quick and easy transfer of information [8]. One consequence of this is individually tailored alternatives that offer content for personal counseling or alternative options based on automation, such as a level support system. In periods of COVID-19, HEI is characterized by online lectures and seminars amongst others, in contrast to HEI routine before the pandemic. The need for regular presence lectures has decreased. However, students currently face greater challenges regarding 
their intrinsic motivation in terms of studying. According to a nationwide study that deals with "Studying digitally in Corona times", more than $50 \%$ of the respondents state that, among other factors, self-organization is strongly difficult [9]. Following Wolters and Hussain [10] though, self-regulating abilities to self-study are considered key to completing HEI studies successfully. Self-regulatory competencies, such as selforganization, goal-oriented learning, etc., becomes increasingly important in context of individualized study. In order to overcome this challenge, the development and introduction of digital assistance systems, such as an individual digital study assistant (IDSA) [11] is a promising opportunity. The development aims to efficiently support students to formulate and achieve their individual educational goals. In this sense, an IDSA promotes self-regulating abilities by providing suitable functionalities. Promoting self-regulating skills is central to the development of an IDSA. Differentiated abilities are associated with helping students set their own goals [12] and to change these goals in a self-observation process [13]. In this way, students can determine whether strategies used serve to achieve goals in terms of a targetperformance comparison [14]. This growing awareness of one's own competences, through target-performance comparisons and in interaction with (big) data and information, is another way to support the individuality of study programs. An IDSA can then take into account performance-related data (e.g., examination results and European Credit Transfer and Accumulation System (ECTS), other data (e.g., qualitative data from dialogues or feedback) from learning and campus management systems (LMS and CMS) and also data from external sources (e.g., from open educational resources (OER) platforms). By collecting information interactively, an IDSA can help students to organize and structure their studies. Situation-specific instructions, reminders, recommendations, and comparisons can enable individual, factual, and social reference norms and further standards. In this way and with growing self-regulating competencies, the increasing trend towards individualization, flexibility, internationalization, and networking can be countered. Accordingly, it is essential to understand the different phases students are going through during their study. A student life cycle (SLC) offers a clear structure in a HEI's diversity, shows all study phases, and merge them [15]. With the SLC, different needs can be better identified. It enables to meet functionalities appropriately. The combined analysis of DSA functionalities and SLC is therefore necessary for a successful, i.e., cost-efficient and accepted student-centered, IDSA development, introduction, and adaption.

DSA research has increased dramatically in the last decade. We focus on DSA functionalities and outline our body of knowledge. Thus, a literature and operated DSA review is performed, and the status quo of existing functionalities is analyzed. Based on our findings, we develop a morphological box with common DSA functionalities and further introduce a research agenda for an IDSA development, introduction, adaption, and success. In this respect, we concentrate on the following research questions:

RQ1: What is the status quo of typical DSA functionalities in HEI aligned to a SLC?

RQ2: What are further research topics for the development, adaption, introduction, and success of an IDSA in HEI considering a SLC? 
First, we discuss the theoretical foundations of DSA and a typical SLC in HEI. Based on this, we describe our research design and methodology, followed by an elaboration of our results, including a morphological box. Afterwards, our results and findings are discussed, and implications and recommendations for research and practice are derived. A further research agenda, limitations, and conclusions complete our paper.

\section{Theoretical Foundations}

\subsection{DSA in HEI}

HEI structures and conditions have changed, e.g., because of HEI's digital transformation [16]. To address this, various digital systems have already been developed and used in the HEI context. Chatbots (also known as conversational agents, talkbots, chatterbots, artificial conversational entities, and virtual assistants) provide a natural language interface to process inputs from its users for an intelligent humancomputer conversation. They usually are equipped with artificial intelligence and various data within, e.g., a knowledge base to react to the user's input and give answers [17-19]. Learning-oriented conversational agents used in the educational context are called pedagogical conversational agents (PCA) [20]. Different research and studies have been carried out in this emerging research stream. Meyer von Wolff et al. [17] conducted a quantitative survey and identified requirements for a HEI chatbot implementation and essential topics to cover. They were able to show that students are willing to use such a system and that it is reasonable in the HEI context. Winkler and Söllner [18] conducted a literature review in which they identified the individual student's diversity, a chatbot's building, and an educational process quality all influence a chatbot's effectiveness. In another literature review, Hobert and Meyer von Wolff [21] outlined that the amount of research in the field of PCA increased, with a trend for messenger-like PCA. The usage is mostly not restricted to a specific learning setting because of their mobile access and students can learn individually. More practically, Hobert [22], for example, introduced a learning system based on a chatbot that helps students to learn to program. According to Knote et al. [22] chatbot assistances are one out of five smart personal assistants (SPA) archetypes, besides adaptive voice (vision) assistants, embodied virtual assistants, passive pervasive assistants, and natural conversation assistants. Thereby, "SPAs are software agents that can automate and ease many of the daily tasks of their users by engaging with them via voice-based, natural language dialog [...]. [They] comprise all types of voice-based software systems that enable humans to hold goal-oriented, natural conversations with computers [...]" [24 p. 3].

A further opportunity to respond to the changes in the HEI is the implementation of an IDSA. In accordance with the previously introduced definitions, we define an IDSA as an efficient digital student support tool that helps to achieve individual educational goals through a connection of previously unrelated data and information, considering individual goals, interests, and the sensitization of own competencies. This interactive information gathering helps students to organize and structure their study with 
situation-specific guidance, reminders, and recommendations. Aligning with the introduced clusters for SPA by Knote et al. [23], an IDSA can have similar design characteristics to fit into the identified archetypes. It supports students in strengthening their self-organization and self-regulation skills, enabling them to organize and manage their studies individually. An IDSA does not support students in direct learning or training of content such as a PCA does with, e.g., learning for an exam. Instead, an IDSA offers tasks that deal with learning topics at a level of reflection.

\subsection{Student Life Cycle}

The SLC concept was initially introduced as a result of the need to professionalize administrative and IT-supported study processes. It enables efficient handling of interfaces to study organization and quality management systems [25]. SLC is also based on models of organizational research. In particular, theories of stakeholders and strategic management theories [26], [27], process-structured organizational systems, and functions of service and customer relations of a HEI are used [28], [29]. All relevant tasks and areas of students, lecturers, and HEI administrations in connection with courses are part of the SLC [15]. In general, the following phases can be highlighted [30]: (1) orientation, (2) application for a university place and enrollment, (3) participation in courses and examinations, (4) graduation and de-registration, as well as (5) alumni activities.

Structure and focus of SLC differ in teaching [31], [25], quality management [32], and cost of a CMS [15]. Bates and Hayes [33] note that students need more intensive support in the transition phase for important and sustainable decisions. Wymbs [34] emphasizes that much electronic data is already collected during the enrollment process. This data can be used for example to provide individual support for the decision-making process in the search for a suitable degree program by matching selfassessment data with artificial intelligence (AI) data. Overall, the focus is to act studentcentered within the study phases. Therefore, different requirements for an IDSA can be concluded.

In the HEI environment, ongoing digital transformations lead to a broad spectrum of study programs, seminars, and lectures with various methodological-didactic and media-based designs. In this context, a SLC as an organizational structure offers a binding set of rules for students, lectures, and HEI administration, and thus provides stability in its diversity [25]. In particular, a dynamic SLC has the potential to divide the organization of studies into specific phases by defining support, information, and service activities for each phase [35]. Regarding the development of support and functionalities, we use the SLC by Sprenger et al. [15]. The following three stages encompass structured sub-dimensions that in turn provide orientation for developing and introducing DSA functionalities, see Tab. 1. 
Table 1. Conceptualization based on SLC [15]

\begin{tabular}{|c|c|c|c|c|c|}
\hline $\begin{array}{l}\text { Before } \\
\text { University } \\
\text { Study }\end{array}$ & recruitment & application & \multicolumn{2}{|c|}{$\begin{array}{l}\text { admission } \\
\text { procedures }\end{array}$} & $\begin{array}{l}\text { enrollment/ } \\
\text { registration }\end{array}$ \\
\hline \multirow{2}{*}{$\begin{array}{l}\text { During } \\
\text { University } \\
\text { Study }\end{array}$} & $\begin{array}{l}\text { examination } \\
\text { procedures }\end{array}$ & \multicolumn{2}{|c|}{$\begin{array}{l}\text { changing course of } \\
\text { study }\end{array}$} & \multicolumn{2}{|c|}{$\begin{array}{l}\text { preparation of } \\
\text { performance reports }\end{array}$} \\
\hline & $\begin{array}{l}\text { organization of } \\
\text { exams }\end{array}$ & \multicolumn{2}{|c|}{$\begin{array}{l}\text { scheduling of } \\
\text { classes, events, and } \\
\text { rooms }\end{array}$} & \multicolumn{2}{|c|}{ re-registration } \\
\hline $\begin{array}{l}\text { After } \\
\text { University } \\
\text { Study } \\
\end{array}$ & \multicolumn{2}{|l|}{ graduation } & \multicolumn{3}{|c|}{ alumni activities } \\
\hline
\end{tabular}

\section{$3 \quad$ Research Design and Methodology}

We conducted a literature review in the field of DSA and its functionalities to answer our research questions. We focused on scientific publications on DSA and followed Webster and Watson [36], Templier and Paré [37], and especially vom Brocke et al. [38], [39]. Vom Brocke et al. [38] propose guidelines for literature reviews to cope with today's literature overload. We followed these guidelines and shortly describe our research steps to ensure transferability and reproducibility. For a detailed overview of our review process, see our protocol available at https://seafile.cloud.unihannover.de/f/275bf02a8c034bffb35b/?dl=1.

Review scope: We used Cooper's taxonomy [40] to extract the characteristics for our literature review. It aims to determine the status quo of DSA and its functionalities in HEI aligned with the SLC on a conceptual level and further identify existing research gaps for an IDSA development, introduction, adoption, and success. We therefore focused on research outcomes and research applications, however, rather from an espousal position. Our literature review and status quo analysis intended to identify a representative coverage of today's functionalities of DSA in scientific literature and operated by HEI. Results are helpful for practitioners as well as general and specialized scholars.

Conceptualization of the topic: We relied on the introduced definition for an IDSA in the previous section. Based on Gumhold and Weber [41] and Fernandes et al. [42] we first investigated DSA in scientific publications in general to get an overview. However, as there already exist some DSA operated in HEI we also conducted a status quo analysis of startups without a scientific foundation. The outcome of this initial conceptualization formed our keywords for further analysis. We distinguished the identified papers and operated DSA in HEI regarding their functionalities for the different SLC phases. Here, we differed between functionalities for the phases before-, during-, and after finishing university study, see Tab. 1.

Literature and operated DSA search: First, we used a keyword search in IS databases to identify relevant literature and functionalities, as those databases include a great number of conferences and journals. Fig. 1 shows the whole search process. In 
doing so, our initial search resulted in 1047 papers and 27 operated DSA in either English or German. To compromise our first findings, we reviewed the titles, abstracts, and keywords of the identified literature and excluded duplicates. This led us to take a closer look at 209 papers. Here, we defined inclusion and exclusion criteria to compromise the remaining papers and ensure their relevance [39]. We analyzed the papers in more detail to decide whether or not to define them as relevant and further tested running DSA. We additionally conducted forward-, backward-, author-, and similarity searches for the most important papers (Google Scholar). Through these processes, we identified 54 relevant papers and 23 operated DSA for a detailed analysis to determine the status quo of DSA functionalities for HEI aligned with the SLC, and to derive a research agenda.

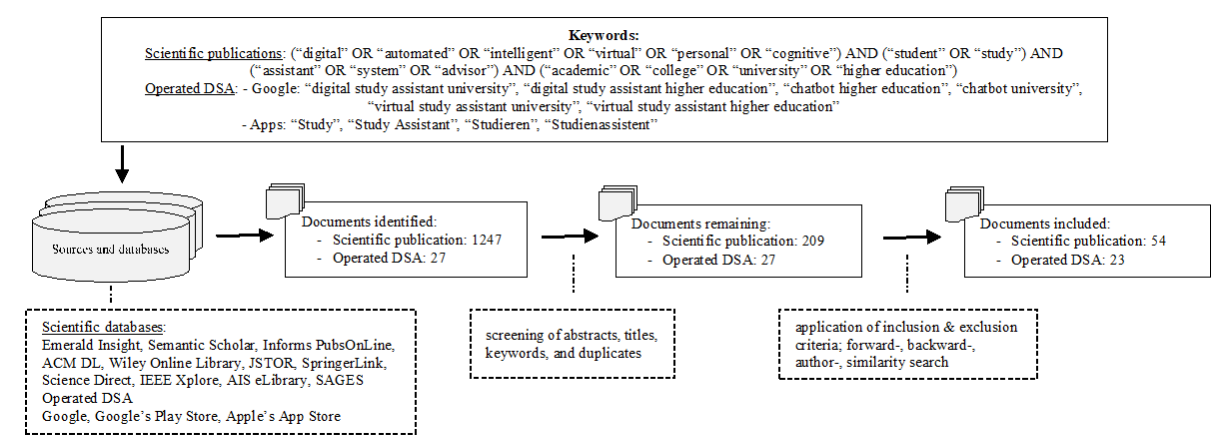

Figure 1. Overview of our Review Process

Literature and operated DSA analysis and synthesis: In the next phase, we analyzed and synthesized the identified literature focusing on the functionalities of a DSA. We used the SLC mentioned above to structure the results and categorized DSA functionalities into the phases before-, during-, and after university study. Based hereon, we derived a morphological box, which is an early output of a morphological analysis. The morphological analysis itself has its origin in the engineering sector but is now also used in numerous different areas, e.g., in energy informatics and social science, often as a systematic creativity technique to generate new ideas for occurring challenges, products, or artifacts. The first step of a morphological analysis is to identify and define dimensions to describe the analyzed system's generic aspects, followed by a definition of explicit design options (characteristics) in a next step. All information is stored in a matrix, the morphological box. It is possible to identify different design options (configurations) by selecting one characteristic for each dimension [42]. The morphological box enables a structured view of underlying features and challenges and allows a systematic perspective with numerous possible solutions [44]. Depending on the objectives and existing conditions of a DSA, we identified various functionalities. For our morphological box, we therefore used the SLC stages [15] as dimensions to structure the findings. Different functionalities then served as characteristics for the morphological box. 
Further research agenda: In a last step, we used our results and findings, i.e., mainly the derived morphological box, to derive implications and recommendations for further research and derived a research agenda for an IDSA development, introduction, adaption, and success.

\section{$4 \quad$ Results and Findings}

Fig. 2 shows the descriptive analysis of the identified publications regarding the number of publications per year from 2003 onwards. It shows that the yearly number increases in a long way. Except from 2003, initial research started in 2009, with most of the research published since 2017 . We thus conclude that there is a rising interest in this research field.

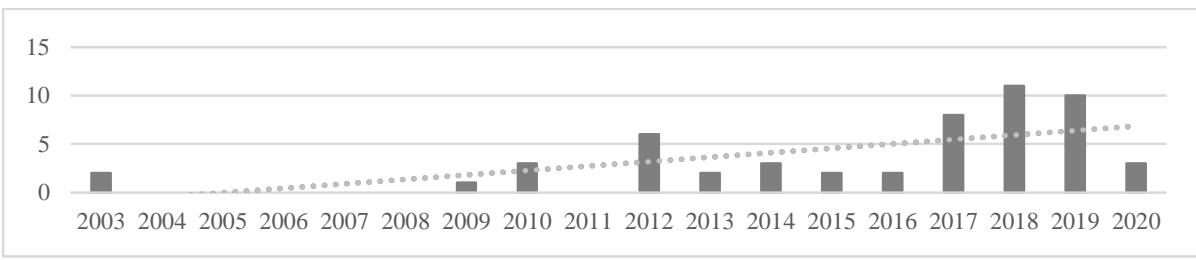

Figure 2. Scientific Publications per Year regarding DSA in HEI

Based on the SLC [15], we structured our findings for DSA functionalities of our literature review and status quo analysis. Each of these SLC phases is further divided into specific activities. However, we excluded or merged some phases and selected those where a DSA application is possible and reasonable according to literature and/or running DSA. As the first step of the morphological analysis, the morphological box gives an overview of potential DSA functionalities in specific study phases. The aim is individual student support to promote self-regulating abilities in a demand-oriented way by digitally providing differentiated functionalities.

Before University Study: Through our literature review and status quo analysis, we were able to identify different functionalities of a DSA for the sub-dimension recruitment, application, and enrollment. However, none for the admission procedure, which is why we excluded it from further analysis and in the morphological box. For the recruitment sub-dimension, Page and Gehlbach [45] introduced a DSA "Pounce" that inter alia supports students in the transition from high school to college by providing personal guidance in this process. In case students are still unsure about field of study decisions, we identified different DSA functionalities. Some assistants provide a link with all faculties and fields of studies with detailed descriptions and study organization, e.g. [46]. On request, some DSA provide further information and links to related modules and credit points, e.g., [47]. Others additionally link to a selfassessment. Here interests are queried and a student's profile is generated. Based on this, individual suitable courses of study and information are then displayed (e.g., [48]). Some DSA are limited to functionalities for this sub-dimensions only. Jamil and Jarot [49] introduced a degree selection system to help students individually select the most 
suitable degree. "SAGES" is a further example [50]. It individually suggests majors and appropriates institutions for new and incoming students, based on, e.g., qualifications, competencies, interests, and city preferences.

The sub-dimension application includes admission and application-related functionalities [51]. Ravikumar et al. [52] introduced a DSA that guides students through the HEI application. Bani and Singh's [53] DSA is limited to this subdimension. They invented a chatbot that focuses explicitly on individual questions and problems that arise during and after the admission process and helps to solves them. Ranoliya et al. [54] presented a DSA that can answer FAQ, including those related to admission. "DINA" [55], as well as the DSA from Lalwani et al. [56] are dialogoriented and directly answer questions related to, e.g., admission processes, requirements, and the HEI's ranking. Others rather provide links to these inquiries to give further information, e.g., [46]. In the case a DSA cannot answer questions or give information, it is either possible to chat with an agent or the DSA provides contact details for further information, e.g., [57].

Once introduced, some DSA provide functionalities for the sub-dimension of enrollment, e.g., [58]. The "KUSE Chatbot" [59] provides information on where to inform about this process and links to the page to do the enrollment. The DSA "Pounce" [45] supports students with activities related to enrollment. Once committed, it individually, proactively, and continually gets in touch with students until they express the intention to study at another HEI, which ultimately increased the enrollment rates. However, only a restricted number of DSA in literature as well as in practice addressed this sub-dimension.

During University Study: For this phase, we also focused on sources supported by our literature and status quo analysis. Therefore, we operated with these subdimensions in the morphological box: performance reports, organization of exams and assessments, distance learning, planning of examinations, changing course of studies, and scheduling of classes and events. Organization of exams and assessments provides a way for students to understand how they are learning through a learning self-test and individual evaluation. An individual checklist or an individual learning tip of the day offer an example of individual provision by linking data and functionalities [69], [70].

Scheduling is a function frequently found in the literature that supports students in organizing their individual daily routine of seminars and examinations [26], [60], [61]. Furthermore, Suvethan et al. [62] pursued the goal of supporting students with FAQ on administrative issues in $1^{\text {st }}$ level support and also to provide them with a human advisor $\left(2^{\text {nd }}\right.$ and $3^{\text {rd }}$ level support). Another functionality is the feedback analysis required for each selected course and an automatic scheduler. Nwankwo [60] offered individual course registrations, course plans, assignments, scholarships, and regulations through the "AdvisorBot". Chen et al. [63] aimed to increase campus life's efficiency by using various campus resources, such as location-based messaging services, resource sharing, appointment management, and student social networking.

In addition, the sub-dimension of examination and enrollment is assigned different functionalities. Dibitonto et al. [58] provided with the DSA "LiSA" general and enrollment information supported by push function about individual deadlines and messages. In a double procedure, these are sent by e-mail and by the DSA at the same 
time. Henderson [64] focused with the developed DSA "AdviseMe" especially on the oral examination qualification. Gumhold and Weber [41] emphasized the attribute of interpreting the examination regulations.

A further sub-dimension describes the performance report. Muangnak et al. [59] worked with a dialogue-based system within their DSA that deals with applying scholarships and credit points for student activities. In addition to students, teachers are supported by operating with AI. Kamal [65] created a recommendation tool that can filter the information using the opinion of other people predicting a student's individual academic performance and interest for a course based on a collection of profiles of students who have similar interests and academic performance on prior courses. Nwankwo [60] developed a tool that records performance profiles from admission time and individually recommends exams based on the profile.

A next field is the function distance lecture. First experiments with transatlantic lectures are described by Herder et al. [66]. The DSA "Genius" [61] is used to provide OER or distance lectures. The recommendation mode offers lectures of individual interest to students.

A combination of functionalities described in the literature forms the activity of changing courses. The functionalities of the recruitment procedure can also be used here. Fernandes et al. [42] are developing a DSA that collects and evaluates personal data from students and provides individual feedback. Based on this, it makes recommendations, e.g., with regard to study programs. Jid Almahri et al. [67] also operated by means of machine learning (ML), designing a persona template for university students that supports the creation of data-driven personas. Among others, data is collected from students to evaluate cognitive engagement, performance expectations, and effort expectations. With this data, profiles can be created to help students learn to assess themselves better to make better study subjects choices.

After University Study: Graduation and alumni both are sub-dimensions of this phase. However, neither in the literature nor in the operated DSA we were able to identify functionalities for the sub-dimension of graduation. Thus, we excluded it from the morphological box. For the sub-dimension of alumni, some DSA provided a linkage to the alumni network's website with further information and possibilities [48], [57]. Others provided a list of alumni with their name and employer, accessible by a link [68]. These two functionalities were the only ones we were able to find during our research process.

Based on our literature review and operated DSA findings, we developed a morphological box, cf. Tab. 2. While we used the three different study phases mentioned above as dimensions with their specific activities as sub-dimensions, the identified functionalities serve as characteristics. Resulting, our morphological box consists of three dimensions, nine sub-dimensions, and various characteristics. 
Table 2. Morphological Box for DSA Functionalities

\begin{tabular}{|c|c|c|c|c|c|c|}
\hline \multicolumn{2}{|c|}{ (Sub-) Dimension } & \multicolumn{4}{|l|}{ Characteristic } & Source \\
\hline \multirow{5}{*}{ 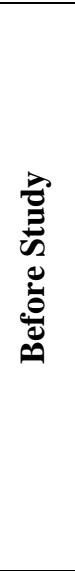 } & \multirow[t]{2}{*}{ recruitment } & $\begin{array}{l}\text { personal } \\
\text { guidance }\end{array}$ & $\begin{array}{l}\text { degre } \\
\text { selec } \\
\text { syste }\end{array}$ & & $\begin{array}{l}\text { link to faculty / } \\
\text { field } \\
\text { information }\end{array}$ & \multirow[t]{2}{*}{$\begin{array}{l}{[45],[46],} \\
{[48-50],} \\
{[57]}\end{array}$} \\
\hline & & \multicolumn{2}{|c|}{$\begin{array}{l}\text { link to self-assessment } \\
\text { with recommendations }\end{array}$} & \multicolumn{2}{|c|}{$\begin{array}{l}\text { majors and institution } \\
\text { suggestion }\end{array}$} & \\
\hline & \multirow[t]{2}{*}{ application } & $\begin{array}{l}\text { guidance } \\
\text { through } \\
\text { application }\end{array}$ & $\begin{array}{l}\text { conta } \\
\text { detail }\end{array}$ & & $\begin{array}{l}\text { questions \& } \\
\text { problems } \\
\text { answering }\end{array}$ & \multirow[t]{2}{*}{$\begin{array}{l}{[46],} \\
{[51-57]}\end{array}$} \\
\hline & & \multicolumn{2}{|l|}{$\begin{array}{l}\text { link for further } \\
\text { information }\end{array}$} & \multicolumn{2}{|c|}{ FAQ admission } & \\
\hline & enrollment & $\begin{array}{l}\text { link for further } \\
\text { information }\end{array}$ & \multicolumn{2}{|c|}{$\begin{array}{l}\text { information } \\
\text { where to } \\
\text { inform }\end{array}$} & $\begin{array}{l}\text { proactive } \\
\text { demand for } \\
\text { status }\end{array}$ & $\begin{array}{l}{[45],[58],} \\
{[59]}\end{array}$ \\
\hline \multirow{6}{*}{ 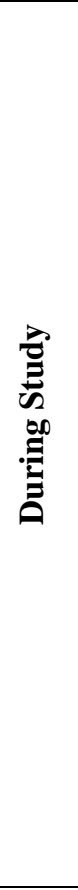 } & $\begin{array}{l}\text { exam } \\
\text { procedures }\end{array}$ & $\begin{array}{l}\text { enrollment } \\
\text { reminder \& } \\
\text { notification }\end{array}$ & \multicolumn{2}{|c|}{$\begin{array}{l}\text { automated } \\
\text { enrollment }\end{array}$} & $\begin{array}{l}\text { link to } \\
\text { enrollment page }\end{array}$ & $\begin{array}{l}{[52],[60],} \\
{[62],[63]}\end{array}$ \\
\hline & $\begin{array}{l}\text { scheduling } \\
\text { of classes } \\
\text { and exams }\end{array}$ & $\begin{array}{l}\text { manual entry in } \\
\text { calendar }\end{array}$ & \multicolumn{2}{|c|}{$\begin{array}{l}\text { automated } \\
\text { entry in } \\
\text { calendar }\end{array}$} & $\begin{array}{l}\text { schedule } \\
\text { optimization }\end{array}$ & $\begin{array}{l}{[26],[60],} \\
{[61]}\end{array}$ \\
\hline & $\begin{array}{l}\text { organization } \\
\text { of exams / } \\
\text { assessments }\end{array}$ & $\begin{array}{l}\text { self-test: } \\
\text { learning } \\
\text { strategies } \\
\text { during studies }\end{array}$ & \multicolumn{2}{|c|}{$\begin{array}{l}\text { individual } \\
\text { checklist: } \\
\text { learning } \\
\text { strategies }\end{array}$} & $\begin{array}{l}\text { individual } \\
\text { learning tips } \\
\text { of the day }\end{array}$ & [69],[70] \\
\hline & $\begin{array}{l}\text { performance } \\
\text { report }\end{array}$ & \multicolumn{2}{|c|}{$\begin{array}{l}\text { completed / open } \\
\text { modules, grades, } \\
\text { comparison to peers }\end{array}$} & \multicolumn{2}{|c|}{\begin{tabular}{|l} 
SWOT analysis \\
based on modules \\
and grades with \\
course suggestion
\end{tabular}} & $\begin{array}{l}{[60],[59],} \\
{[65]}\end{array}$ \\
\hline & $\begin{array}{l}\text { changing } \\
\text { course of } \\
\text { studies } \\
\end{array}$ & $\begin{array}{l}\text { self-assessment } \\
\text { with a persona } \\
\text { template }\end{array}$ & \multicolumn{2}{|c|}{$\begin{array}{l}\text { majors and } \\
\text { institution } \\
\text { suggestion }\end{array}$} & $\begin{array}{l}\text { link for further } \\
\text { information }\end{array}$ & {$[42],[67]$} \\
\hline & $\begin{array}{l}\text { distance } \\
\text { lecture }\end{array}$ & $\begin{array}{l}\text { outside one's } \\
\text { own HEI with } \\
\text { OER and other } \\
\text { media }\end{array}$ & \multicolumn{2}{|c|}{$\begin{array}{l}\text { within } \\
\text { one's own } \\
\text { HEI }\end{array}$} & $\begin{array}{l}\text { outside one's } \\
\text { own HEI with } \\
\text { participation of } \\
\text { different HEI }\end{array}$ & {$[66],[61]$} \\
\hline 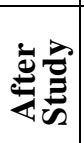 & alumni & \multicolumn{3}{|c|}{ link to list of graduates } & $\begin{array}{l}\text { k to alumni } \\
\text { twork }\end{array}$ & $\begin{array}{l}{[48],[57],} \\
{[68]}\end{array}$ \\
\hline
\end{tabular}




\section{Discussion, Implications, and Recommendations}

While the number of students has steadily increased [2], the amount of lecturers has remained almost constant [5], [6]. Due to the Bologna Process, diversity amongst students has equally inclined over the last 20 years. Thus, the proportion of individual counseling has also risen [4]. In addition, digital transformation processes have accelerated within the framework of HEI since the presence of COVID-19. This is especially obvious by drawing attention to the increasing online lectures and other offerings. In this connection, the study on "Online in Corona-times" [9] highlights that the topic of self-regulated study is becoming the focus of attention.

The majority of students is socialized in the digital environment which is reflected, for example, in changing information behavior. Especially today, students desire quick and easy information transfer [8]. We see this development as an opportunity to support students individually by dealing with the research topic IDSA, which we address by asking two research-questions. The first step here is to determine the status quo of DSA functionalities through a structured literature review, which is organized by the SLC. Our literature review has shown that while the first DSA developments took place in the 1990s [71], the majority was introduced in the last decade, see Fig. 1. The authors present different types and functionalities of a DSA, e.g., [62], but often without empirical evaluation. This includes studies that address both stakeholder requirements as well as the usefulness and relevance of DSA. This observation is also supported by the fact that DSA are increasingly found in status quo analysis but are often developed without any research before being introduced in HEI.

A critical point is that we deduced the requirements of potential users for a DSA within the SLC framework exclusively based on theory. From this systematic evaluation and our focus on designing individual support for students, a modification towards an IDSA is the next crucial step. To achieve this, we mapped our results in a morphological box. As a method of analysis and development, we designed functionality gradations. Thereby, more attention is paid to the variety of functionalities in the phase during study compared to the period before and after study. A functionality frequently described in literature is the organization of daily seminars and examination life in miscellaneous variations, see, e.g., [52]. This observation supports the increasing and diverse range of offers, whether in the context of seminars, working materials, or in the diversity of the study programs themselves. The question arises if the focus of functionality distribution follows a swarm research's core study, i.e., in research communities, this phase is considered relevant.

An IDSA development, introduction, and adaption in HEI structured along the SLC is the second research question, as further research topics become apparent with the focus on functionalities. For example, no stakeholder survey exists yet. The introduction of an IDSA is also linked to HEI's maturity as it determines whether an IDSA can be introduced and continued. For this study, we only considered the functionalities, whereas exploration of non-functionalities becomes equally important because in addition to maturity, it also decides whether an IDSA will be used. We developed a research agenda with additional topics and research questions, inspired by 
our findings, the morphological box, and theory-based, presented in Tab. 3 as an overview.

Table 3. Overview of the Extracted Further Research Agenda

\begin{tabular}{|c|c|}
\hline Topics for a Further Research Agenda & Research Questions \\
\hline $\begin{array}{l}\text { The IDSA development and potential } \\
\text { functionalities are dependent on the IT } \\
\text { maturity of an HEI. There is a need to } \\
\text { develop such an IT maturity model for a } \\
\text { IDSA development, introduction, and } \\
\text { adoption cf. e.g., [3]. }\end{array}$ & $\begin{array}{l}\text { How does the IT maturity level of a } \\
\text { HEI influence an IDSA development, } \\
\text { adaption, introduction, and success? }\end{array}$ \\
\hline $\begin{array}{l}\text { Many stakeholders influence the IDSA } \\
\text { development, introduction, and usage, but } \\
\text { they have not yet been all identified, cf. e.g., } \\
\text { [39], [51]. }\end{array}$ & $\begin{array}{l}\text { What are typical stakeholders for an } \\
\text { IDSA development, introduction, } \\
\text { adoption, and operation? }\end{array}$ \\
\hline $\begin{array}{l}\text { Many DSA in practice as well as in research } \\
\text { are introduced. However, there often is a } \\
\text { lack of foundations for developed } \\
\text { functionalities and their usefulness. It } \\
\text { requires more studies to firstly identify } \\
\text { needs and requirements, and secondly an } \\
\text { IDSA's usefulness and relevance, cf. e.g., } \\
\text { [61], [62]. }\end{array}$ & $\begin{array}{l}\text { (1) What are typical requirements of } \\
\text { all stakeholders for an IDSA } \\
\text { development, introduction, adoption, } \\
\text { and success? } \\
\text { (2) How useful and relevant are } \\
\text { operated IDSA? }\end{array}$ \\
\hline $\begin{array}{l}\text { We excluded some activities from the SLC } \\
\text { in our morphological box, as there were no } \\
\text { functionalities yet. For others, there only } \\
\text { exist few functionalities yet, cf. e.g., [4]. }\end{array}$ & $\begin{array}{l}\text { (1) What are especially important } \\
\text { activities for an IDSA operation? } \\
\text { (2) How can IDSA functionalities be } \\
\text { further developed to include all } \\
\text { activities of a typical SLC? }\end{array}$ \\
\hline $\begin{array}{l}\text { We restricted the functionalities on those } \\
\text { within the SLC. However, there are } \\
\text { important activities students undergo, e.g., } \\
\text { [72]. }\end{array}$ & $\begin{array}{l}\text { What are further important } \\
\text { functionalities of an IDSA outside a } \\
\text { typical SLC? }\end{array}$ \\
\hline $\begin{array}{l}\text { We focused on the functionalities of a DSA. } \\
\text { There is a need to also identify non- } \\
\text { functional requirements, cf. e.g., [56], [60]. }\end{array}$ & $\begin{array}{l}\text { What are non-functional requirements } \\
\text { for an IDSA development, } \\
\text { introduction, adoption, and success? }\end{array}$ \\
\hline $\begin{array}{l}\text { We focused on the functionalities for all } \\
\text { phases of the SLC. However, different } \\
\text { phases require an IDSA more than others, } \\
\text { which has not yet been identified, cf. e.g., } \\
\text { [45] [59]. }\end{array}$ & $\begin{array}{l}\text { Which phases within a typical SLC } \\
\text { can be best supported by an IDSA? }\end{array}$ \\
\hline
\end{tabular}




\section{Conclusions and Limitations}

With an increasing number and heterogeneity of students and the increasing availability of educational resources, an IDSA has the potential to individually support students in getting information and advice quickly, easily, and automatically. Especially in times of COVID-19, an IDSA becomes even more important to support students in their digital semesters. We conducted a literature review and status quo analysis of existing DSA. As a result, we identified the status quo of typical DSA functionalities aligned to a SLC. Based on a morphological box, we structured the functionalities in the phases before-, during-, and after university study. While important functionalities for the before university study phase range from a degree selection system to application guidance, the visualization of completed and open modules with grades as well as the provision of OER are DSA functionalities during the study and a linkage to an alumni network after finishing study. Based on our results and findings, we additionally discussed an agenda for further research for an IDSA development, introduction, adoption, and success in this nascent field.

However, the literature selection and analysis are both influenced by our subjective perceptions, which might weaken our results. With the application of inclusion and exclusion criteria, we tried to minimize this subjective influence as much as possible. We further only identified a representative coverage of existing functionalities and these cannot be fully exhaustive. For the operated DSA, we limited our searches to Google, Google's Play Store, and Apple's App Store. There are more databases or platforms, e.g., LMS, to identify further DSA. Additionally, our morphological box resulted from our findings from the literature and status quo analysis, i.e., without expertise from different DSA stakeholders. It only discussed the status quo without evaluating the functionalities' relevance and usefulness for different stakeholders.

Our results and findings contribute to both research and practice. Researchers can build on the research agenda to close research gaps and address research needs. For HEI practitioners, the morphological box gives a structured overview of commonly used DSA functionalities. This is especially important for the development, introduction, adaption, and success of an IDSA.

\section{Acknowledgement}

Our research project "SIDDATA" is funded by the German Federal Ministry of Education and Research (FKZ 16DHB2123).

\section{References}

1. Brändle, T.: 10 Jahre Bologna-Prozess - Chancen, Herausforderungen und Problematiken. Springer, Wiesbaden (2010)

2. OECD.: Number of Students (indicator). Tertiary 1995-2020, https://data.oecd.org/eduresource/number-of-students.htm (Accessed: August 28, 2020) 
3. Clarke, J., Nelson, K., Stoodley, I.: The Place of Higher Education Institutions in Assessing Student Engagement, Success and Retention: A Maturity Model to Guide Practice. In: Wyse, P., Billot, J., Frielick, S., Hallas J., Whitehead, E., Buissink-Smith, N. (eds.) Research and Development in Higher Education: The Place of Learning and Teaching 36, pp. 91-101 (2013)

4. Wong, B.T.M., Li, K.C.: Using Open Educational Resources for Teaching in Higher Education: A Review of Case Studies. Proceedings of the International Symposium on Educational Technology (2019)

5. Klammer, U.: Diversity Management und Hochschulentwicklung. In: Kergel, D., Heidkamp, B. (eds.) Praxishandbuch Habitussensibilität und Diversität in der Hochschullehre, pp. 45-69. Springer VS, Wiesbaden (2019)

6. Hornsby, D.J., Osman, R.: Massification in Higher Education: Large Classes and Student Learning. Higher Education 67, pp. 711-719 (2014)

7. Marczok, Y.M.: Blended Learning as a Response to Student Heterogeneity. Managing Innovation and Diversity in Knowledge Society Through Turbulent Time. Proceedings of the MakeLearn and TIIM Joint International Conference (2016)

8. Gikas, J., Grant, M.M.: Mobile Computing Devices in Higher Education: Student Perspectives on Learning with Cellphones, Smartphones \& Social Media. Internet and Higher Education 19, pp. 18-26 (2013)

9. Traus, A., Höffken, K., Thomas, S., Mangold, K., Schroer, W.: Stu.diCo. Studieren digital in zeiten von Corona. Universitätsverlag Hildesheim. https://doi.org/10.18442/150 (Accessed: November 18.2020)

10. Wolters C.A., Hussain, M.: Investigating Grit and its Relations with College Students' SelfRegulated Learning and Academic Achievement. Metacognition and Learning 10, pp. 293$311(2015)$

11. Murphy, M.P.A.: COVID-19 and Emergency eLearning: Consequences of the Securitization of Higher Education for Post-Pandemic Pedagogy. Contemporary Security Policy, pp. 492505 (2020)

12. Zimmerman, B.: Goal Setting: A Key Proactive Source of Academic Self-Regulation. In: Schunk, D.H., Zimmerman, B. (eds.) pp. 267-296, Taylor and Francis Group, New York (2012)

13. Vanslambrouk, S., Zhu, C., Lombaerts, K., Philipsen, B., Tondeur, J.: Students' Motivation and Subjective Task Value of Participating in Online and Blended Learning Environments. The Internet and Higher Education 36, pp. 33-40 (2018)

14. Schunk, D.H.: Self-regulated Learning: The Educational Legacy of Paul R. Pintrich. Educational Psychologist 40, pp. 85-94 (2015)

15. Sprenger, J., Klages, M., Breitner, M.H.: Cost-Benefit Analysis for the Selection, Migration, and Operation of a Campus Management System. Business \& Information Systems Engineering 2, pp. 219-231 (2010)

16. Bennett, S., Agostinho, S., Lockyer, L.: Technology Tools to Support Learning Design: Implications Derived from an Investigation of University Teachers' Design Practices. Computers \& Education 81, pp. 211-220 (2015)

17. Meyer von Wolff, R., Nörtemann, J., Hobert, S., Schumann, M.: Chatbots for the Information Acquisition at Universities - A Student's View on the Application Area. In: Følstad, A., Araujo, T., Papadopoulos, S., Law, L.-C., Granmo, O.-C., Luger, E., Brandtzaeg, P.B. (eds.) Chatbot Research and Design. Third International Workshop, CONVERSATIONS 2019, pp. 231-244. Springer, Cham (2020)

18. Winkler, R., Söllner, M.: Unleashing the Potential of Chatbots in Education: A State-OfThe-Art Analysis. Academy of Management Proceedings (2018) 
19. Mikic, F.A., Burguillo, J.C., Llamas, M., Rodriguez, D.A., Rodriguez, E.: CHARLIE: An AIML-based Chatterbot which Works as an Interface Among INES and Humans. EAEEIE Annual Conference (2009)

20. Wellnhammer, N., Dolata, M., Steigler, S., Schwabe, G.: Studying with the Help of Digital Tutors: Design Aspects of Conversational Agents that Influence the Learning Process. Hawaii International Conference on System Sciences (2020)

21. Hobert, S.; Meyer von Wolff, R.: Say Hello to Your New Automated Tutor - A Structured Literature Review on Pedagogical Conversational Agents. Internationale Tagung Wirtschaftsinformatik (2019)

22. Hobert, S.: Say Hello to 'Coding Tutor'! Design and Evaluation of a Chatbot-based Learning System Supporting Students to Learn to Program. International Conference on Information Systems (2019)

23. Knote, R., Janson, A., Söllner, M., Leimeister, J.M.: Classifying Smart Personal Assistants: An Empirical Cluster Analysis. Hawaii International Conference on System Sciences (2019)

24. Winkler, R., Neuweiler, M.L., Bittner, E., Söllner, M.: Hey Alexa, Please Help Us Solve This Problem! How Interactions with Smart Personal Assistants Improve Group Performance. International Conference on Information Systems (2019)

25. Schulmeister, R.: Der "Student Lifecycle" als Organisationsprinzip für E-Learning. In: Keil, R., Kerres, M., Schulmeister, R. (eds.): eUniversity Update Bologna, pp. 45-78. Waxmann, Münster (2007)

26. Sjöström, J., Aghaee, N., Dahlin, M., Agerfalk, P.: Designing Chatbots for Higher Education Practice. Proceedings of the International Conference on Information Systems Education and Research (2019)

27. Porter, M.E.: Competitive Strategy: Techniques for Analyzing Industries and Competitors. The Free Press, New York (1980)

28. Donabedian, A.: The Definition of Quality and Approaches to Its Assessment - Explorations in Quality Assessment and Monitoring Chicago. Health Administration Press (1980)

29. Sursock, A.: Examining Quality Culture Part II: Processes and Tools - Participation, Ownership and Bureaucracy. European University Association, Brussels (2011)

30. Lizzio, A., Wilson, K.: Student Lifecycle, Transition and Orientation. In: Facilitating Commencing Student Success Across the Lifecycle: Strategic Student Orientation. Griffith University, Brisbane (2012)

31. Harlan, R.: The Automated Student Advisor: A Large Project for Expert Systems Courses. ACM SIGCSE Bulletin 26 (1994)

32. Pohlenz, P., Mitterauer, L., Harris-Huemmert, S.: Qualitätssicherung im Student Life Cycle. Waxmann, Münster (2020)

33. Bates, L., Hayes, H.: Using the Student Lifecycle Approach to Enhance Employability: An Example from Criminology and Criminal Justice. Asia-Pacific Journal of Cooperative Education, Special Issue 18, pp. 141-151 (2017)

34. Wymbs, C.: Make Better Use of Data Across the Student Life Cycle. Enrollement Management Report 20, p. 8 (2016)

35. Gaisch, M., Aichinger, R.: Pathways for the Establishment of an Inclusive Higher Education Governance System: An Innovative Approach for Diversity Management. Proposal for the EAIR Forum Birmingham (2016)

36. Webster, J., Watson, R.T.: Analyzing the Past to Prepare for the Future: Writing a Literature Review. MIS Quarterly 26, xiii-xxiii (2002)

37. Templier, M., Paré, G.: A Framework for Guiding and Evaluating Literature Reviews. Communications of the Association for Information Systems 37, (2015) 
38. Vom Brocke, J., Simons, A., Niehaves, B., Reimer, K., Plattfaut, R., Cleven, A.: Reconstructing the Giant: On the Importance of Rigour in Documenting the Literature Search Process. Proceedings of the European Conference on Information Systems (2009)

39. Vom Brocke, J., Simons, A., Riemer, K., Niehaves, B., Plattfaut, R., Cleven, A.: Standing on the Shoulders of Giants: Challenges and Recommendations of Literature Search in Information Systems Research. Communications of the Association for Information Systems 37, pp. 205-224 (2015)

40. Cooper, H.M.: Organizing Knowledge Syntheses. A Taxonomy of Literature Reviews. Knowledge in Society 1, pp. 104-126 (1988)

41. Gumhold, M., Weber, M.: SASy - A Study Assistance System. Proceedings of the International Conference on New Educational Environments (2003)

42. Fernandes, J., Raposo, D., Armando, N., Sinche, S., Sá Silva, J., Rodrigues, A., Pereira, V., Gonçalo Oliveira, H., Macedo, L., and Boavida, F.: ISABELA - A Socially-Aware Humanin-the-Loop Advisor System. Journal Online Social Networks and Media 16, 100063 (2020)

43. Ritchey, T.: Modeling Alternative Futures with General Morphological Analysis. World Futures Review 3, pp. 83-94 (2011)

44. Jantsch, E.: Technological Forecasting in Perspective. OECD, Paris (1976)

45. Page, L., Gehlbach, H.: How an Artificially Intelligent Virtual Assistant Helps Students Navigate the Road to College. AERA Open 3, pp. 1-12 (2017)

46. Universität Wien, https://ucard.univie.ac.at/studierende/ (Accessed: August 28, 2020)

47. Technische Universität Berlin, https://alex.qu.tu-berlin.de/ (Accessed: August 28, 2020)

48. Universität Innsbruck, https://www.uibk.ac.at/studium/ (Accessed: August 28, 2020)

49. Jamil, R., Jarot, S.P.W.: Intelligent Decision Support System for Degree Selection Using AHP Technique. Proceedings of the International Conference on Computer and Communication Engineering (2012)

50. Bouaiachi, Y., Khaldi, M., Azmani, A.: A Prototype Expert System for Academic Orientation and Student Major Selection. International Journal of Scientific \& Engineering Research 5, pp. 25-28 (2014)

51. Patel, N.P., Parikh, D.R., Patel, D.A., Patel, R.R.: AI and Web-Based Human-Like Interactive University Chatbot (UNIBOT). Proceedings of the International Conference on Electronics Communication and Aerospace Technology (2019)

52. Ravikumar, R., Rajan, A.V., Abdulla, A., Ahamed, J.: A Proposal for Introducing Virtual Reality Assistant at Dubai Women's College. Proceedings of the HCT Information Technology Trends (2017)

53. Bani, B.S., Singh, P.: College Enquiry Chatbot Using A.L.I.C.E. International Journal of New Technology and Research 3, pp. 64-65 (2017)

54. Ranoliya, B.R., Raghuwanshi, N., Singh, S.: Chatbot for University Related FAQs. Proceedings of the International Conference on Advances in Computing, Communications and Informatics (2017)

55. Santoso, H.A., Winarsih, N.A.S., Mulyanto, E., Saraswati, G.W., Sukmana, S.E., Rustad, S., Rohman, M.S., Nugraha, A., Firdausillah, F.: Dinus Intelligent Assistance (DINA) Chatbot for University Admission Service. Proceedings of the International Seminar on Application for Technology of Information and Communication (2018)

56. Lalwani, T., Bhalotia, S., Pal, A., Bisen, S., Rathod, V.: Implementation of a Chatbot System using AI and NLP. International Journal of Innovative Research in Computer Science \& Technology 6, pp. 26-30 (2018)

57. Creighton University, https://doit.creighton.edu/services-provided-doit/ask-iggy (Accessed: 28.08.2020) 
58. Dibitonto, M., Leszczynska, K., Tazzi, F., Medaglia, C. M.: Chatbot in a Campus Environment: Design of LiSA, a Virtual Assistant to Help Students in Their University Life. Proceedings of the International Conference on Human-Computer Interaction (2018)

59. Muangnak, N., Thasnas, N., Hengsanunkul, T., Yotapakdee, J.: The Neural Network Conversation Model Enables the Commonly Asked Student Query Agents. International Journal of Advanced Computer Science and Applications 11, pp. 154-164 (2020)

60. Nwankwo, W.: Interactive Advising with Bots: Improving Academic Excellence in Educational Establishments. American Journal of Operations Management and Information Systems 3, pp. 6-21 (2018)

61. Scheepers, R., Lacity, M.C., Willcocks, L.P.: Cognitive Automation as Part of Deakin. MIS Quarterly Executive 17, pp. 89-107 (2018)

62. Suvethan, N., Avenash, K., Huzaim, M.A.Q., Mathusagar, R., Gamage, M.P.A.W., Imbulpitiya, A.: Virtual Student Advisor using NLP and Automatic Appointment Scheduler and Feedback Analyser. International Journal of Scientific and Engineering Research 7, pp. 155-160 (2019)

63. Chen, Z., Xia, F., Cheng, R., Kang, J., Li, C.: OnCampus: A Mobile Personal Assistant for College Students. International Conference on Computers in Education (2012)

64. Henderson, K.L., Goodridge, W.: AdviseMe: An Intelligent Web-Based Application for Academic Advising. International Journal of Advanced Computer Science and Applications 6, pp. 233-243 (2015)

65. Kamal, T.: Automatic Academic Advisor. International Conference on Collaborative Computing: Networking, Applications and Worksharing (2012)

66. Herder, P.M., Subrahmanian, E., Talukdar, S., Turk, A.L., Westerberg, A.W.: The Use of Video-Taped Lectures and Web-Based Communications in Teaching: A Distance-Teaching and Cross-Atlantic Collaboration Experiment. European Journal of Engineering Education 27, pp. 39-48 (2002)

67. Jid Almahri, F.A.A., Bell, D., Arzoky, M.: Personas Design for Conversational Systems in Education. Informatics 6, pp. 1-26 (2019)

68. Technische Universität Darmstadt, https://hermine-winf.de/ (Accessed: August 28.2020)

69. Klingsieck, K.: Kurz und knapp - die Kurzskala des Fragebogens "Lernstrategien im Studium" (LIST). Zeitschrift für pädagogische Psychologie, 32, pp. 249-259 (2018)

70. Roth, A., Orgin, S., Schmitzl, B.: Assessing Self-Regulated Learning in Higher Education: A Systematic Literature Review of Self-Report Instruments. Educational Assessment, Evaluation and Accountability 28, pp. 225-250 (2016)

71. Harlan, R.: The Automated Student Advisor: A Large Project for Expert Systems Courses. ACM SIGCSE Bulletin 26 (1994)

72. Université Paris-Saclay: https://www.universite-paris-saclay.fr/en/campuslife/international-welcome-desk (Accessed: 28.08.2020) 